\title{
Can guidelines inhibit innovation and critical thinking?
}

\author{
Shaun R. McCann ${ }^{1}$
}

Received: 23 January 2020 / Revised: 29 January 2020 / Accepted: 30 January 2020 / Published online: 6 February 2020

(c) Springer Nature Limited 2020

'We started off trying to set up a small anarchist community, but people wouldn't obey the rules'

\section{Alan Bennett 1934-English playwright.}

Guidelines are in the air. There are guidelines now for nearly everything including HCT. Although guidelines can be very useful the 'law of unintended consequences' may come into play. Guidelines should be short and should clearly explain that they cannot cover all clinical situations and are merely to help in coming to a rational decision. They are certainly useful in planning strategy. For example, we decided, a number of years ago, to carry out five allogeneic HCT for renal cell carcinoma and evaluate the results. Following evaluation, we stopped. I should confess to taking part in the publication of a 20-page guideline for the investigation and treatment of a certain syndrome. Useless. Perhaps a chapter in a book but definitely not a guideline. A recent example is ASH guidelines for management of venous thromboembolism: prophylaxis for hospitalised and nonhospitalised patients [1]. This guideline was 20 pages long, contained 174 references and concluded: the limitations of these guidelines are inherent in the low or very low certainty in the evidence we identified for many of the questions!

A prominent surgeon in Ireland told me that in his view the next generation of doctors will be unable to make a clinical decision without consulting guidelines.

Unfortunately, members of the judiciary in some countries, do not seem to understand this and think that guidelines are rules which cannot be broken. Could it be that guidelines stymie the ability to think clearly? A colleague (she is head of a large HCT unit) said recently that while on a ward round with her staff she encountered a critically ill post HCT patient. Turning to her staff, she asked: 'what

Shaun R. McCann

shaunrmccann@gmail.com

Emeritus Haematology, Trinity College Dublin, Dublin, Ireland would you do'? The answer from all staff members came loudly and clearly: 'consult the guidelines', 'discuss the case at the next MDT' (multidisciplinary conference)'. These were trainees in a large university teaching hospital! My colleague believed that a decision needed to be made immediately and that the answer would probably not be found in the guidelines. In Henry Hemmings book 'Our Man in New York': 'Charles Lindberg (not everyone's favourite person) was quoted as saying; 'forming committees was one of the greatest of American fallacies' [2]. Serendipity and common sense are two expressions that doctors do not like but we would not have penicillin or the discovery of Helicobacter Pylori as a cause of peptic ulcer disease/gastric cancer without serendipity.

Some people [2] believe that observational databases combined with expert opinion provide reliable and effective ways of determining effective new therapies in the HCT setting. Some people also believe that evidence is objective. Of course, it is subjective and depends on the way it is collected and presented. Otherwise the world would not need lawyers.

The diagnosis and treatment of acute graft-versus-host disease is a good example of the very limited value of guidelines. In the 2019 EBMT handbook [3] Holler, Greinix and Zeiser say that: 'so far no single agent has shown superiority of results when combined with corticosteroids for first line treatment of acute Graft versus Host Disease $(a G v H D)$ ' yet many different approaches to the treatment of aGvHD are found in established HCT units. In a recent interview [4] Professor James Ferrara said: 'we need a simpler system of grading and staging of GvHD. It was so confusing that we asked our pathologists to stop grading the biopsies'.

So, there are many clinical situations in HCT units in which the decisions reached will vary between hospitals, and guidelines, if they exist, are of little value.

What about wine making? Yes, there are recommendations but there are many variations in fermentation strategies, from the use of cement, stainless steel, wood, and more latterly the use of the cement 'egg'. The cement egg 


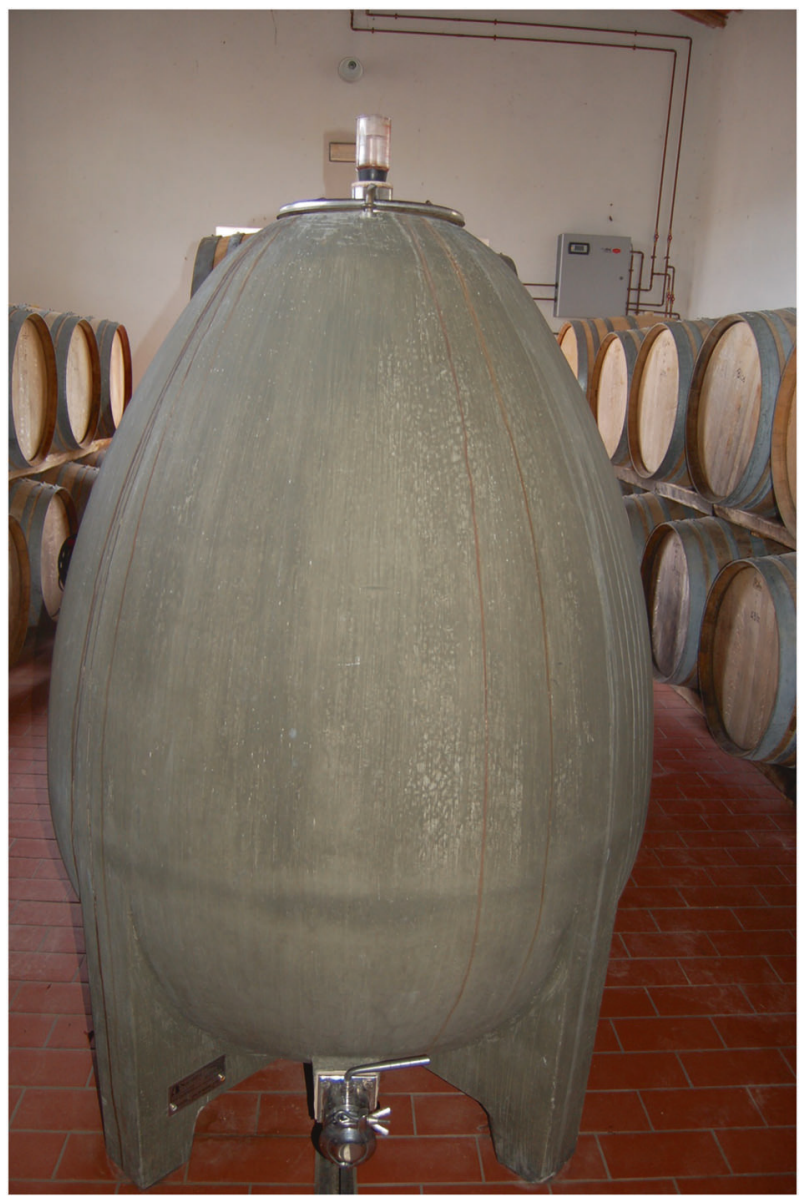

Fig. 1 Cement 'egg' for fermentation, Poggerino, Tuscany.

was developed by Joseph Francois and exhibited at the trade fair in Milan, Italy in 2011. As wine ferments heat is produced and the 'egg' is credited with facilitating gentle and continual mixing of the cooler and warmer wine during the fermentation process. I have tasted wine fermented in an 'egg' by my good friend Piero Lanza in his cantina in Poggerino outside Radda in Tuscany (Fig. 1). The egg shape is somewhat similar to the amphorae (Fig. 2) used in ancient times. I confess that I was unable to discern the difference in his wine fermented in the 'egg' or the more traditional way. This is undoubtedly due to a deficiency on my part.

We have alluded to the different types of closure before but some areas e.g., Chianti Classico insist on cork closure being used if the wine is to receive the Gallo Nero symbol (Fig. 3). The Gallo Nero symbol on the neck of bottles of Chianti Classico is a form of quality control. The symbol of the black rooster is reputedly based on the medieval legend of the dividing line between the territories of Florence and Siena having been the symbol of the Chianti Military League since the 14th century. In this case the Gallo Nero symbol guarantees that the wine is from the Chianti

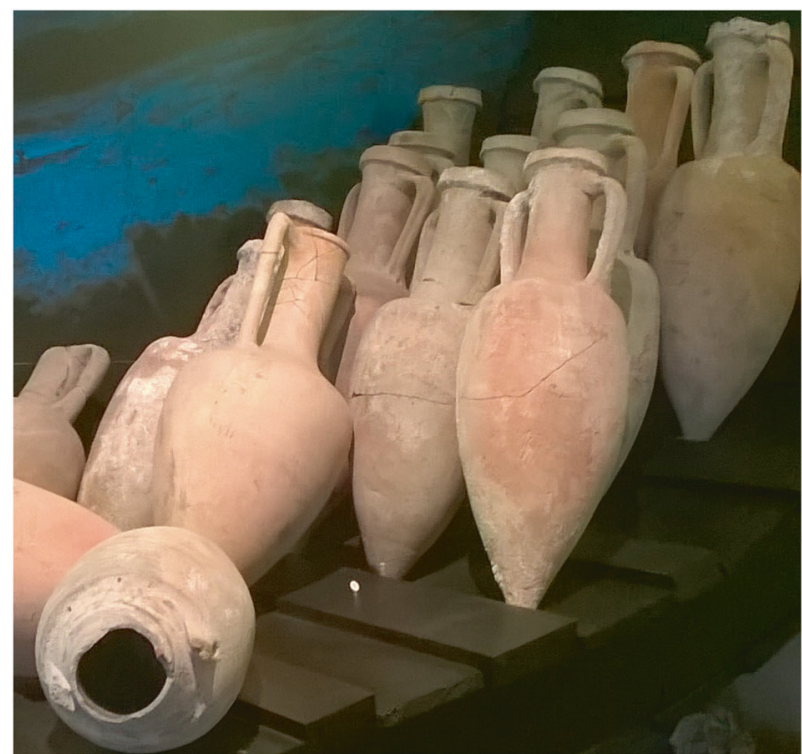

Fig. 2 Amphorae used to ferment and store wine in ancient times.

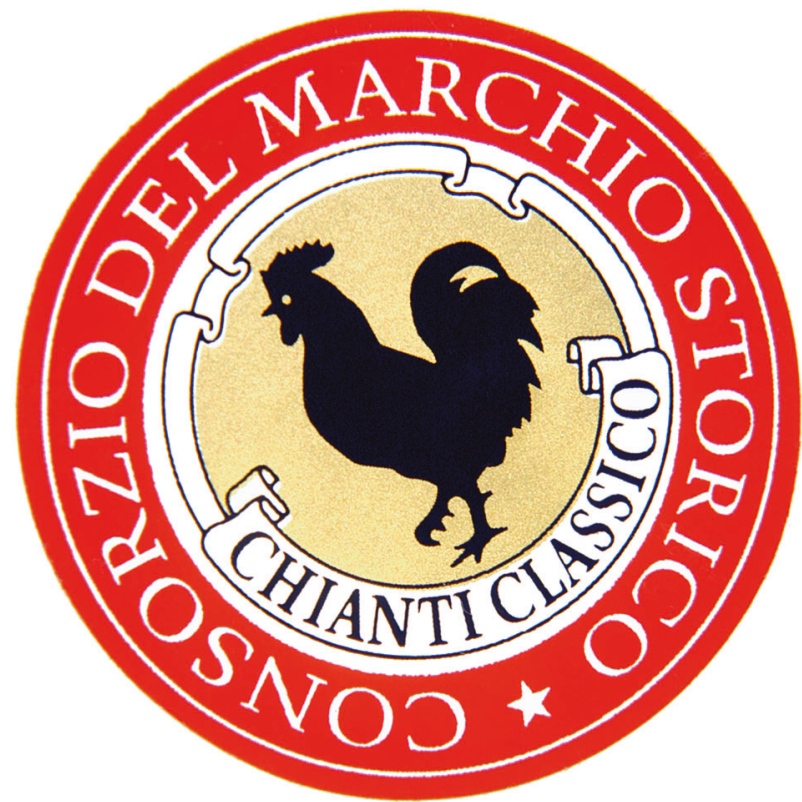

Fig. 3 Gallo Nero symbol.

Classico area and is made from Sangiovese grapes (75-100\%) with the other $25 \%$ being made from Colorino up to $15 \%$, Caniolo up to $10 \%$, Trebbiano and Malvasia up to $6 \%$ and Cabernet Sauvignon or Merlot up to 15\% [5]. My own preference if for Chianti Classico made predominantly from Sangiovese, up to $100 \%$. However, there many excellent Chianti Classicos which do not have the Gallo Nero symbol.

So, guidelines are useful in medicine and wine making but there is always room for 'critical thinking' and the use of common sense and experience to guide one's decision making. 


\section{Compliance with ethical standards}

Conflict of interest The author declares that he has no conflict of interest.

Publisher's note Springer Nature remains neutral with regard to jurisdictional claims in published maps and institutional affiliations.

\section{References}

1. Schünemann JH, Cushman M, Burnett AE, Kahn SR, BeyerWestendorf J, Spencer F, et al. American Society of Hematology 2018 guidelines for management of venous thromboembolism: prophylaxis for hospitalized and nonhospitalized medical patients. Blood Adv Am Soc Hematol. 2019;2:3198-225.

2. Gale RP, Eapen M, Logan B, Zhang M-J, Lazarus HM. Are there roles for observational database studies and structured quantification of expert opinion to answer therapy controversies in transplants? Bone Marrow Transplant. 2009;43:435-46.

3. Henry Hemmings. Chapter 13. In: Our Man in New York. London: Quercus Editions Ltd; 2019. ISBN 978-1787474833.

4. Carreras E, Dufour C, Mohty M, and Kröger N. Hematopoietic Cell Transplantation. Chapter 43. In: The EBMT Handbook. Fondation José Carreras. Switzerland: Springer Open; 2019. ISBN 978-3030022778.

5. Giovanni Branchetti Montorselli, editor. Catalogue of Chianti Classico producers. Consorzio del Marchio Storico Chianti Classico. San Casciano, Florence: Black Rooster Wines; 2001. 